Thorax (1949), 4, 73.

\title{
THE RESERVE AIR AS AN AID IN THE DIAGNOSIS OF EMPHYSEMA
}

\author{
BY \\ H. HERXHEIMER \\ From the Surgical Unit and Chest Department, University College Hospital, London
}

The main signs of severe emphysema, deformation of the chest, hyper-resonant percussion note, and harsh breath sounds with numerous rhonchi caused by the accompanying bronchitis, are well known and permit a diagnosis without difficulty. However, there are many cases of moderate emphysema in which none of these signs, or only some, are present. Their diagnosis causes great difficulty. Christie (1944) has therefore said in a review that he prefers to rely for his diagnosis at least as much on the history and the typical symptom of increasing breathlessness on exertion as on the signs. In these circumstances it is desirable to improve the accuracy of this diagnosis.

It is generally recognized that the mid-capacity of the lungs in emphysema is increased. The midcapacity is the sum of the residual air, reserve air, and half the tidal air. It is increased because the lungs become over-inflated. This is "emphysema" in its widest sense. It occurs as a transient change in muscular exercise, excitement, and $\mathrm{CO}_{2}$ breathing, and any expiratory resistance may provoke it. Verzár (1933) has called this transient increase of the mid-capacity the third form of regulation of the respiration, since the increase of the midcapacity increases the respiratory surface. These transient changes can be observed in many healthy subjects and cannot be regarded as abnormal. If they become permanent pathological emphysema has developed. It is uncertain at which stage of this development anatomical changes-rarefaction of the respiratory epithelium, atrophy of blood vessels, and, later, bullae-appear. They may be present at its beginning, or in other cases may appear only as a result of continuous over-inflation. As it is not possible to estimate the degree of anatomical changes by clinical methods, I shall use the term "emphysema," without regard to the anatomical change, to denote a continuous state of over-inflation of the lungs.

An increased mid-capacity must be shown before the presence of emphysema can be assumed. This means, if one disregards the unimportant half tidal air as a constituent of the mid-capacity, the proof of an increased functional residual air, using Christie's (1933) terminology. This consists of the residual air proper which cannot be removed from the lungs by any exertion, and of the reserve air which can be exhaled by voluntary expiratory effort. The determination of the residual air is complicated, and the methods at our disposal are of doubtful value in emphysema. The reserve air, however, is easily determined by a recording spirometer.

If the tidal air movement is carried out by lungs more inflated than normal, it means that during an ordinary expiration the lungs do not recoil as fully as normal lungs. It must not be taken to imply that they cannot be compressed by external forces, or that the reserve air could not be emptied by voluntary effort. Therefore we should expect an increased reserve air in emphysema as long as the muscular forces of the body are capable of compressing the chest. This increase will not be evident if these forces are diminished by atrophy of the muscles or other causes, or if they are insufficient to overcome obstacles hindering compression -for instance, bronchial spasm or skeletal changes. If these obstacles prevent full compression of the chest by the muscles we cannot expect an enlarged reserve air. That part of it which cannot be exhaled because of obstruction or muscular inefficiency becomes part of the residual air. In such cases the reserve air will appear normal or even small, and the vital capacity will be reduced accordingly.

\section{EXPERIMENTAL STUdies}

Experimental Expiratory Stenosis : Artificial Emphysema.-If a normal subject is connected with a recording spirometer and expiration obstructed by a screw clip on the expiratory tube, it can be seen that at once the amount of air in the chest increases. The tidal air level rises steeply and finally establishes itself on a higher plane. If now the maximum inspiration and expiration are taken 
(the routine method of recording the vital capacity and its subdivisions), it will be seen that the reserve air has increased from about $30 \%$ of the vital capacity, a normal percentage, to, for instance, $50 \%$, which is abnormally high. If a thoracometer tracing is made it will be seen that, at the same time as the tidal air level on the spirometer drum rises, the circumference of the chest increases correspondingly. This confirms that the chest volume increases. The movements of the diaphragm have also been followed up radiologically in five experiments. In every case the diaphragm assumed a lower level during the expiratory stenosis. As soon as the screw clip is removed, the tidal air resumes its former level. Fig. 1 gives an example from the experiment, with spirometer and thoracometer tracings synchronized ; Fig. 2 gives another without the thoracometer tracing. If the tracing of a typical patient with moderate emphysema* with good costal and diaphragmatic movement (Fig. 3) is compared with the tracing of a normal subject during experimental stenosis (Fig. 1, lower part, and Fig. 2), hardly any difference can be found. In the first case we have an artificial, transient emphysema, in the second a permanent one. In both the muscular strength of ribs and diaphragm is sufficient, but without an expiratory effort the emphysema persists. and the reserve air remains enlarged. As the vital capacity is normal in both cases, it seems probable that the residual air

*This subject had the typical histery of emphysema; the vital capacity was very little reduced; the degree of asthmatic spasm was small and easily controlled ; the diaphragmatic level was radiologically lower than normal.

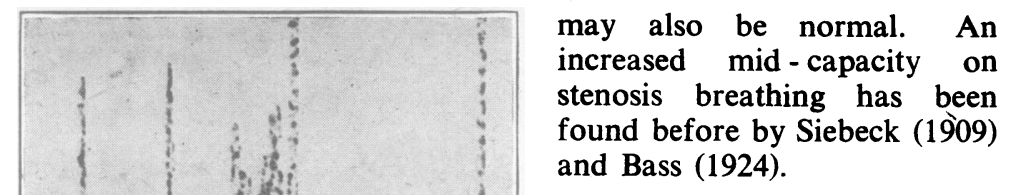

Diaphragmatic Action and Reserve Air.-It is well known that in emphysematous persons the diaphragm is found at an abnormally low level. Grossmann and Herxheimer (1948) have described a radiological method of measuring this level. They found a lowered diaphragm not only in severe but also in moderate emphysema. If the diaphragm is fully mobile and the lungs can be compressed, little or no bronchial spasm being present, the expiratory movement of the diaphragm must be much greater from a low than from a normal level. Therefore, the reserve air must be larger in an emphysematous subject, if the upward movement of the diaphragm is the main factor in the movement of the reserve air. This is indeed the case, as I have been able to confirm by comparing the thoracometric and spirometric tracings (Herx heimer, 1949). Whereas in the movement of the complemental air the ribs take a great part, the reserve air is mainly moved by the abdominal muscles causing the upward movement of the diaphragm. If, therefore, the diaphragm in emphysema is found low, the reserve air must be expected

FIG. 1.-EFFeCT OF EXPIRATORY OBSTRUCTION.-(Upper tracing, thoracogram; lower tracing, spirogram.) From A to $\mathrm{B}$ expiration was partially obstructed by a screw clip. Note that the reserve air is increased during this period (the reserve air $C D$ is $76 \%$ of the vital capacity against the normal reserve air $\mathrm{EF}=$ $36 \%$ ). 

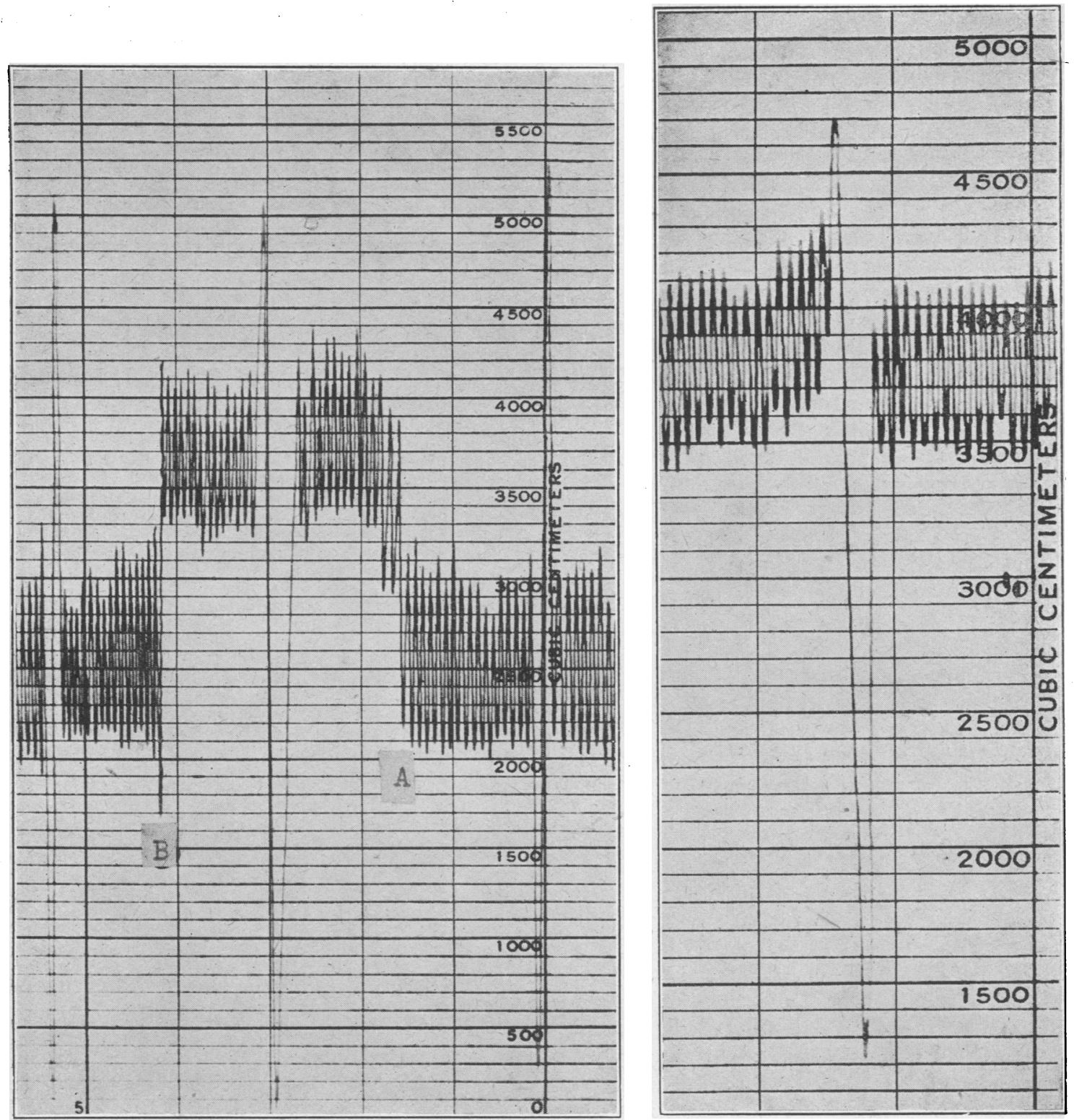

Fig. 2.-Normal Subject. Experimental stenosis between A and B. Fig. 3.-Emphysema. Note the similarity between this tracing and the part from $A$ to $B$ on Fig. 2.

to be large, except in cases in which the chest cannot be emptied normally by muscular effort -e.g., in advanced emphysema with severe bronchospasm.

Measurement of the Reserve Air.-In all patients with emphysema seen during the last four years the reserve air has been recorded. Emphysema was assumed to be present if the patient had been $\mathrm{E}^{*}$ increasingly breathless on exertion for some time, if he complained of cough, and if congestive heart failure and localized pulmonary disease had been excluded. Typical clinical signs were present in many, but often there was only one, and often they were not pronounced. The signs frequently absent were deformity of the chest and hyperresonance. In all cases the diaphragm was found 
to be low radiologically, and in many its level had been determined according to the method described by Grossmann and Herxheimer (1948). Asthmatic patients were included either if there was

TABLE I

Reserve AIR In Normal SUbJects

\begin{tabular}{|c|c|c|c|c|}
\hline $\begin{array}{l}\text { Case } \\
\text { No. }\end{array}$ & Age & Sex & $\begin{array}{c}\text { Vital } \\
\text { Capacity } \\
\text { (ml.) }\end{array}$ & $\begin{array}{l}\text { Reserve Air } \\
\text { (Expressed as } \\
\text { Percentage of } \\
\text { Vital Capacity) }\end{array}$ \\
\hline $\begin{array}{r}1 \\
2 \\
3 \\
4 \\
5 \\
6 \\
7 \\
8 \\
9 \\
10 \\
11 \\
12 \\
13 \\
14 \\
15 \\
16 \\
17 \\
18 \\
19 \\
20 \\
21 \\
22 \\
23 \\
24 \\
25 \\
26 \\
27 \\
28 \\
29 \\
30 \\
31 \\
32 \\
33 \\
34 \\
35 \\
36 \\
37 \\
38 \\
39 \\
40 \\
41 \\
42 \\
43 \\
44 \\
45 \\
46 \\
47 \\
48\end{array}$ & $\begin{array}{l}15 \\
15 \\
15 \\
15 \\
16 \\
39 \\
17 \\
16 \\
16 \\
23 \\
23 \\
16 \\
17 \\
21 \\
21 \\
21 \\
21 \\
12 \\
12 \\
11 \\
9 \\
12 \\
12 \\
12 \\
12 \\
17 \\
12 \\
22 \\
21 \\
21 \\
22 \\
21 \\
17 \\
22 \\
21 \\
21 \\
21 \\
21 \\
22 \\
21 \\
26 \\
58 \\
53 \\
16 \\
22 \\
25 \\
25 \\
22\end{array}$ & $\begin{array}{l}\mathbf{M} \\
\mathbf{M} \\
\mathbf{M} \\
\mathbf{M} \\
\mathbf{F} \\
\mathbf{F} \\
\mathbf{F} \\
\mathbf{M} \\
\mathbf{M} \\
\mathbf{F} \\
\mathbf{F} \\
\mathbf{M} \\
\mathbf{M} \\
\mathbf{M} \\
\mathbf{M} \\
\mathbf{M} \\
\mathbf{M} \\
\mathbf{F} \\
\mathbf{F} \\
\mathbf{M} \\
\mathbf{M} \\
\mathbf{M} \\
\mathbf{M} \\
\mathbf{M} \\
\mathbf{M} \\
\mathbf{M} \\
\mathbf{M} \\
\mathbf{M} \\
\mathbf{M} \\
\mathbf{M} \\
\mathbf{F} \\
\mathbf{M} \\
\mathbf{M} \\
\mathbf{F} \\
\mathbf{M} \\
\mathbf{M} \\
\mathbf{M} \\
\mathbf{M} \\
\mathbf{F} \\
\mathbf{M} \\
\mathbf{F} \\
\mathbf{M} \\
\mathbf{M} \\
\mathbf{M} \\
\mathbf{F} \\
\mathbf{F} \\
\mathbf{F} \\
\mathbf{M}\end{array}$ & $\begin{array}{l}3,905 \\
3,500 \\
3,990 \\
4,505 \\
2,890 \\
2,380 \\
3,335 \\
4,280 \\
4,480 \\
3,230 \\
3,740 \\
2,960 \\
4,580 \\
5,020 \\
4,800 \\
5,290 \\
5,565 \\
2,180 \\
2,040 \\
2,055 \\
1,945 \\
1,965 \\
1,700 \\
1,870 \\
1,870 \\
3,170 \\
2,400 \\
4,665 \\
5,480 \\
4,410 \\
3,270 \\
4,475 \\
4,740 \\
3,535 \\
4,120 \\
4,370 \\
5,470 \\
4,400 \\
3,430 \\
3,800 \\
3,870 \\
3,230 \\
3,880 \\
3,775 \\
3,100 \\
4,640 \\
2,800 \\
3,410\end{array}$ & $\begin{array}{l}39 \\
39 \\
31 \\
34 \\
39 \\
37 \\
33 \\
33 \\
36 \\
37 \\
32 \\
36 \\
33 \\
41 \\
34 \\
40 \\
38 \\
40 \\
28 \\
31 \\
36 \\
28 \\
31 \\
23 \\
23 \\
34 \\
24 \\
33 \\
28 \\
29 \\
38 \\
35 \\
32 \\
28 \\
35 \\
26 \\
31 \\
24 \\
37 \\
38 \\
29 \\
34 \\
28 \\
32 \\
29 \\
28 \\
36 \\
34\end{array}$ \\
\hline
\end{tabular}

Average reserve air: $33 \%$ of vital capacity.

deformity or if they were over 30 years old and had suffered from severe bronchial asthma over long and continuous periods for at least 15 years.
This history seemed to justify the assumption that some degree of emphysema was present even if its signs were not pronounced. All other asthmatics were excluded, even if they suffered from breathlessness on exertion.

TABLE II

RESERVE AIR IN EMPHYSEMATOUS AND ASTHMATIC SUBJECTS WITH “NORMAL" AND " High" VITAL CAPACITY

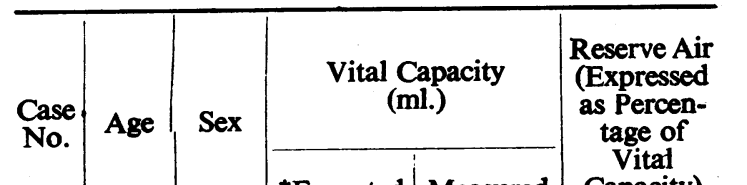

iv

w

\begin{tabular}{|c|c|c|c|c|c|}
\hline & & & & & \\
\hline $\begin{array}{l}1 \\
2 \\
3 \\
4\end{array}$ & $\begin{array}{l}52 \\
34 \\
26 \\
55\end{array}$ & $\begin{array}{l}\mathbf{F} \\
\mathbf{F} \\
\mathbf{M} \\
\mathbf{M}\end{array}$ & $\begin{array}{l}2,350 \\
2,460 \\
3,160 \\
2,800\end{array}$ & $\begin{array}{l}2,415 \\
3,055 \\
3,375 \\
2,955\end{array}$ & $\begin{array}{l}61 \\
45 \\
52 \\
54\end{array}$ \\
\hline
\end{tabular}

\begin{tabular}{c|c|c|c|c|c}
5 & $?$ & $\mathrm{M}$ & 3,130 & 4,120 & 45 \\
6 & 54 & $\mathrm{M}$ & 4,140 & 3,200 & 61
\end{tabular}

\begin{tabular}{ll|l|l|l|l}
7 & 51 & $M$ & 3,980 & 4,380 & 49
\end{tabular}

\begin{tabular}{l|l|l|l|l|l}
8 & 40 & $M$ & 3,300 & 4,320 & 43
\end{tabular}

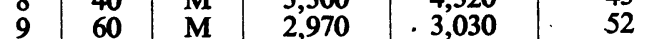

\begin{tabular}{l|l|l|l|l|l}
10 & 42 & M & 3,265 & 3,465 & 71
\end{tabular}

\begin{tabular}{l|l|l|l|l|l}
11 & 23 & $\mathrm{M}$ & 3,190 & 4,455 & 47
\end{tabular}

\begin{tabular}{l|l|l|l|l|l}
12 & 44 & $F$ & 2,540 & 2,955 & 43
\end{tabular}

\begin{tabular}{l|l|l|l|l|l}
13 & 41 & $F$ & 2,510 & 3,045 & 43
\end{tabular}

\begin{tabular}{l|l|l|l|l|l}
14 & 34 & $F$ & 2,810 & 3,050 & 58
\end{tabular}

\begin{tabular}{l|l|l|l|l|l}
15 & 31 & F. & 3,090 & 3,430 & 51
\end{tabular}

\begin{tabular}{l|l|l|l|l|l}
16 & 41 & $F$ & 2,480 & 2,755 & 44
\end{tabular}

\begin{tabular}{l|l|l|l|l|l}
17 & 37 & $\mathrm{M}$ & 3,180 & 3,215 & 38
\end{tabular}

\begin{tabular}{l|l|l|l|l|l}
18 & 57 & M & 2,950 & 3,425 & 53
\end{tabular}

\begin{tabular}{ll|l|l|l|l}
19 & 45 & $\mathrm{~F}$ & 2.320 & 2,625 & 32
\end{tabular}

\begin{tabular}{l|l|l|l|l|l}
20 & 46 & $\mathrm{M}$ & 2,950 & 3,700 & 50
\end{tabular}

\begin{tabular}{l|l|l|l|l|l}
21 & -59 & $M$ & 3,390 & 4,205 & 31
\end{tabular}

2254

$23 \quad 38$

$24 \quad 42$

$25 \quad 25$

$26 \quad 42$

$27 \quad 16$

\begin{tabular}{l|l}
28 & $?$ \\
29 & 31
\end{tabular}

$30 \quad 52$

$31 \quad 23$

$3 2 \longdiv { 3 6 }$

$33 \quad 45$

$34 \quad 45$

$35 \quad 65$

$36 \quad 48$

$37 \quad 35$

\begin{tabular}{l|l|l|}
38 & 31 \\
39 & 46 \\
\hline & 29
\end{tabular}

$40 \quad 29$

$41 \quad 35$

$42 \quad 16$

$43 \quad 36$

\begin{tabular}{l|l|l|}
44 & 16 \\
45 & 20
\end{tabular}

$46 \quad 45$

Average reserve air: $49 \%$ of vital capacity. 
The vital capacity was used to divide these patients into two groups-those with a normal or high vital capacity and those in whom it was reduced. The vital capacity shows great variability even in normal subjects, and it is hardly possible to predict it accurately by any of the usual formulae based on weight or body surface. It had been noticed that there was a correspondence between the reduction in vital capacity and the disability of the patient. It was, therefore, assumed that those with a reduced vital capacity suffered from a more severe degree of the disease. Dreyer's (1920) standards according to weight were taken as an arbitrary limit of the normal. These values are low when compared with the other standards, and therefore it is reasonably certain that values below this limit represent a reduced vital capacity. All other patients were included in the second group. This group thus consists of patients with "normal" vital capacity (some of whom might range as slightly reduced according to other standards) and with vital capacities higher than that. It must be stressed that all these patients had a typical history of increasing breathlessness on exertion and cough or a long history of asthma. Most of them had some clinical sign of emphysema and all of them had radiologically a low-level diaphragm. In all of them signs of bronchitis were present. I believe that these signs and symptoms are sufficient to make the presence of clinical emphysema probable even if the vital capacity is not reduced. Such cases might reasonably be classed as moderate emphysema ; it is possible that they occur much more frequently than is generally assumed. Severe emphysema is known to develop gradually during long periods, and its earlier (moderate) stages are likely to produce less pronounced symptoms and signs than the later ones. The first stages may even cause no symptoms at all and easily escape detection. It seems desirable to detect them, since treatment of them may offer more hope than that of the severe cases.

A number of normal subjects were also investigated to gain material for comparison. These were mostly students and nurses, but a few school children and some out-patients without gross disability and without chest disease were also included. Table I shows the figures obtained in these "normal" subjects. The reserve air, recorded in the sitting position, lies between $20 \%$ and $41 \%$ of the vital capacity. This is well in accordance with the figures obtained by Hurtado and others (1934) and Kaltreider and others (1938). Their averages in different groups of normal subjects lie between $17 \%$ and $23 \%$, and their individual figures vary between $4 \%$ and $38 \%$. As these values were obtained in the supine position, about $12 \%$ must be added, according to Kaltreider's and my own

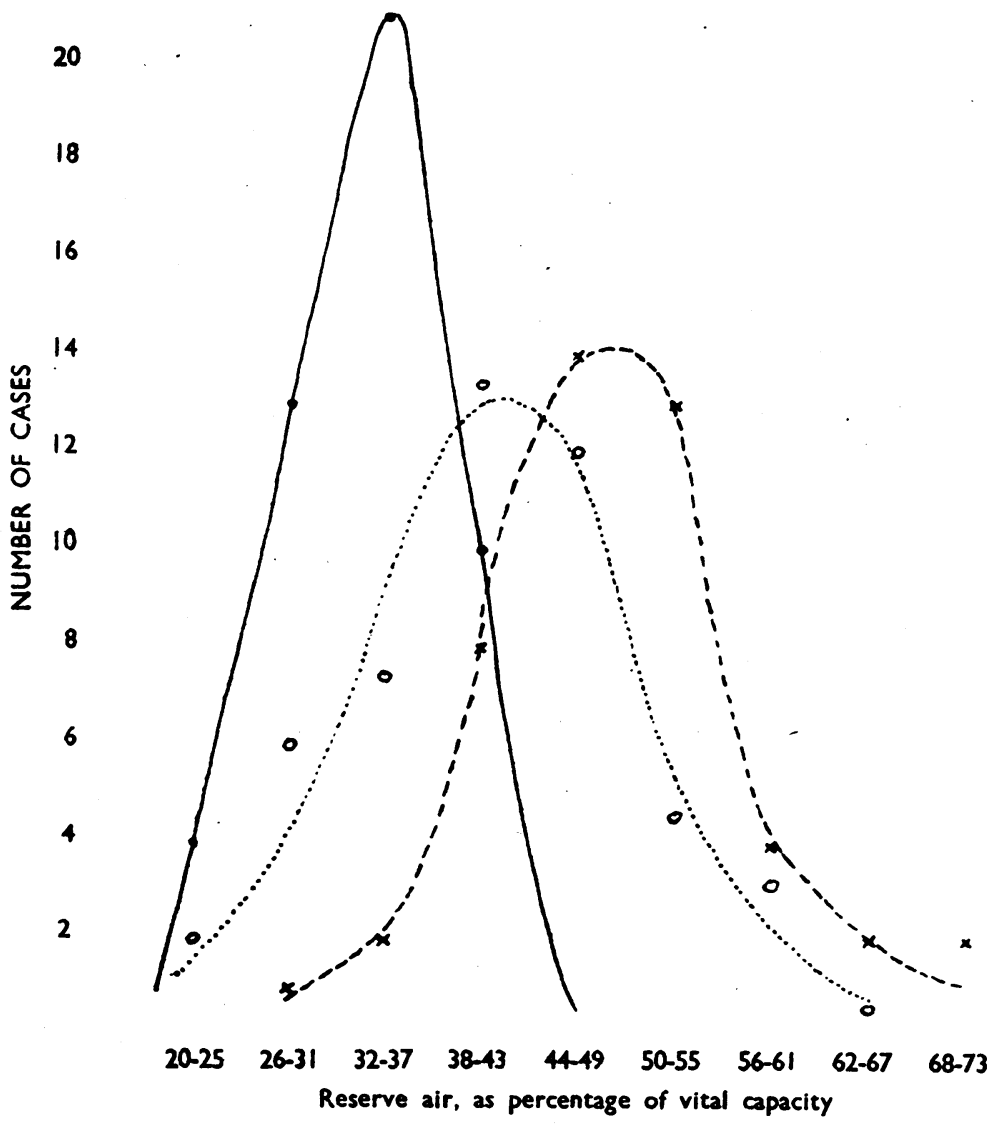

Fig. 4.-Frequency distribution of reserve air percentage in normal and emphysematous subjects. normal subjects. physematous subjects with normal vital capacity. ....... emphysematous subjects with reduced vital capacity. 
(Herxheimer, 1948) experience, in order to compare them with results obtained in the sitting position. Our average of $33 \%$ therefore accords well with the averages of these authors:

Table II shows the results in the patients with " normal" and " high" vital capacity. As mentioned before, these patients were less handicapped by their illness than those whose vital capacity was reduced. Their emphysema was therefore regarded as moderate. Their average reserve air is $49 \%$ against $33 \%$ in the normal subjects, as can be seen from the frequency distribution (Fig. 4). The difference seems significant, as almost all the figures lie above the upper limit of the normal values. Only three patients had a reserve air clearly below that limit. Two of them (20 and 41) had an emphysematous-looking chest with an increased antero-posterior diameter. They were asthmatics with comparatively short histories of one and a half and two years, and the short history may account for the absence of emphysema and of an increased reserve air. The third

TABLE III

Reserve Air in Emphysematous and Asthmatic Subjects with "Reduced" Vital Capacity

\begin{tabular}{|c|c|c|c|c|c|c|c|c|c|c|c|}
\hline \multirow{2}{*}{$\begin{array}{l}\text { Case } \\
\text { No. }\end{array}$} & \multirow{2}{*}{ Age } & \multirow{2}{*}{ Sex } & \multicolumn{2}{|c|}{$\begin{array}{l}\text { Vital Capacity } \\
\text { (ml.) }\end{array}$} & \multirow{2}{*}{$\begin{array}{l}\text { Reserve Air } \\
\text { (Expressed } \\
\text { as Percen- } \\
\text { tage of } \\
\text { Vital } \\
\text { Capacity) }\end{array}$} & \multirow{2}{*}{$\begin{array}{l}\text { Case } \\
\text { No. }\end{array}$} & \multirow{2}{*}{ Age } & \multirow{2}{*}{ Sex } & \multicolumn{2}{|c|}{$\begin{array}{c}\text { Vital Capacity } \\
\text { (ml.) }\end{array}$} & \multirow{2}{*}{$\begin{array}{l}\text { Reserve Air } \\
\text { (Expressed } \\
\text { as Percen- } \\
\text { tage of } \\
\text { Vital } \\
\text { Capacity) }\end{array}$} \\
\hline & & & ${ }^{*}$ Expected & Measured & & & & & ${ }^{*}$ Expected & Measured & \\
\hline $\begin{array}{r}1 \\
2 \\
3 \\
4 \\
5 \\
6 \\
7 \\
8 \\
9 \\
10 \\
11 \\
12 \\
13 \\
14 \\
15 \\
16 \\
17 \\
18 \\
19 \\
20 \\
21 \\
22 \\
23 \\
24 \\
25 \\
26 \\
27 \\
28 \\
29 \\
30 \\
31 \\
32 \\
33 \\
34 \\
35 \\
36 \\
37 \\
38 \\
39\end{array}$ & $\begin{array}{l}58 \\
49 \\
40 \\
63 \\
52 \\
52 \\
50 \\
45 \\
54 \\
50 \\
25 \\
52 \\
14 \\
24 \\
65 \\
62 \\
56 \\
60 \\
58 \\
34 \\
53 \\
58 \\
55 \\
53 \\
46 \\
46 \\
36 \\
32 \\
55 \\
55 \\
46 \\
42 \\
50 \\
57 \\
51 \\
28 \\
36 \\
46 \\
38\end{array}$ & $\begin{array}{l}\mathbf{F} \\
\mathbf{F} \\
\mathbf{F} \\
\mathbf{F} \\
\mathbf{M} \\
\mathbf{M} \\
\mathbf{M} \\
\mathbf{M} \\
\mathbf{M} \\
\mathbf{F} \\
\mathbf{F} \\
\mathbf{F} \\
\mathbf{M} \\
\mathbf{F} \\
\mathbf{M} \\
\mathbf{M} \\
\mathbf{M} \\
\mathbf{M} \\
\mathbf{M} \\
\mathbf{F} \\
\mathbf{F} \\
\mathbf{M} \\
\mathbf{F} \\
\mathbf{F} \\
\mathbf{M} \\
\mathbf{F} \\
\mathbf{F} \\
\mathbf{M} \\
\mathbf{M} \\
\mathbf{F} \\
\mathbf{M} \\
\mathbf{M} \\
\mathbf{M} \\
\mathbf{M} \\
\mathbf{M} \\
\mathbf{F} \\
\mathbf{F} \\
\mathbf{F} \\
\mathbf{M}\end{array}$ & $\begin{array}{l}2,250 \\
2,845 \\
3,030 \\
2,700 \\
2,825 \\
3,660 \\
2,940 \\
3,330 \\
3,080 \\
3,060 \\
2,550 \\
2,800 \\
2,650 \\
1,990 \\
3,210 \\
3,030 \\
3,030 \\
3,370 \\
4,210 \\
2,780 \\
2,530 \\
4,480 \\
3,575 \\
2,570 \\
3,550 \\
3,540 \\
2,550 \\
3,400 \\
3,500 \\
1,910 \\
2,960 \\
3,025 \\
3,180 \\
2,770 \\
3,150 \\
3,230 \\
2,325 \\
2,615 \\
3,100\end{array}$ & $\begin{array}{l}1,895 \\
2,575 \\
2,770 \\
1,455 \\
2,175 \\
2,635 \\
2,480 \\
2,395 \\
2,860 \\
2,170 \\
2,130 \\
1,945 \\
2,435 \\
1,855 \\
3,075 \\
2,950 \\
2,025 \\
2,540 \\
2,730 \\
2,405 \\
1,940 \\
3,764 \\
1,875 \\
1,930 \\
2,780 \\
3,125 \\
2,465 \\
2,955 \\
2,105 \\
1,450 \\
2,030 \\
2,630 \\
2,950 \\
1,930 \\
2,260 \\
2,550 \\
1,610 \\
2,460 \\
3,065\end{array}$ & $\begin{array}{l}41 \\
33 \\
58 \\
20 \\
30 \\
34 \\
45 \\
50 \\
59 \\
32 \\
48 \\
39 \\
40 \\
47 \\
49 \\
49 \\
56 \\
49 \\
44 \\
40 \\
44 \\
34 \\
26 \\
63 \\
41 \\
29 \\
39 \\
28 \\
44 \\
35 \\
45 \\
30 \\
39 \\
36 \\
38 \\
43 \\
44 \\
38 \\
38\end{array}$ & $\begin{array}{l}40 \\
41 \\
42 \\
43 \\
44 \\
45 \\
46 \\
47 \\
48 \\
49 \\
50 \\
51 \\
52 \\
53 \\
54 \\
55 \\
56 \\
57 \\
58 \\
59 \\
60 \\
61 \\
62 \\
63 \\
64 \\
65 \\
66 \\
67 \\
68 \\
69 \\
70 \\
71 \\
72 \\
73 \\
74 \\
75 \\
76 \\
77\end{array}$ & $\begin{array}{l}42 \\
55 \\
57 \\
58 \\
52 \\
57 \\
57 \\
35 \\
43 \\
66 \\
54 \\
26 \\
41 \\
57 \\
52 \\
37 \\
34 \\
53 \\
45 \\
37 \\
23 \\
63 \\
52 \\
34 \\
51 \\
54 \\
33 \\
44 \\
54 \\
49 \\
61 \\
51 \\
56 \\
52 \\
49 \\
38 \\
53 \\
35\end{array}$ & 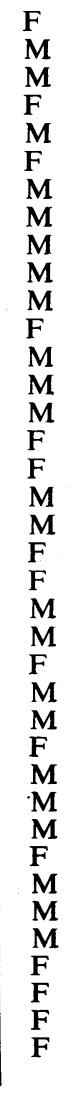 & $\begin{array}{l}3,215 \\
2,770 \\
2,990 \\
2,880 \\
3,520 \\
3,000 \\
3,670 \\
3,420 \\
2,810 \\
3,900 \\
3,860 \\
2,940 \\
3,200 \\
4,260 \\
3,770 \\
2,570 \\
2,730 \\
3,480 \\
3,160 \\
2,860 \\
2,090 \\
3,500 \\
3,405 \\
2,140 \\
2,560 \\
3,660 \\
2,230 \\
3,025 \\
2,810 \\
3,790 \\
1,945 \\
3,080 \\
4,400 \\
4,210 \\
2,140 \\
2,450 \\
2,370 \\
2,440\end{array}$ & $\begin{array}{l}2,850 \\
1,920 \\
2,050 \\
2,160 \\
1,765 \\
2,505 \\
3,280 \\
3,140 \\
1,090 \\
3,150 \\
3,350 \\
2,100 \\
2,675 \\
3,630 \\
3,140 \\
2,560 \\
2,580 \\
2,390 \\
2,490 \\
1,900 \\
1,970 \\
1,770 \\
2,650 \\
1,480 \\
2,310 \\
3,440 \\
1,915 \\
2,730 \\
2,365 \\
3,070 \\
1,435 \\
1,960 \\
3,550 \\
3,510 \\
1,700 \\
2,010 \\
1,300 \\
1,730\end{array}$ & $\begin{array}{l}31 \\
48 \\
58 \\
25 \\
32 \\
41 \\
44 \\
52 \\
43 \\
34 \\
46 \\
28 \\
26 \\
41 \\
40 \\
40 \\
37 \\
54 \\
48 \\
28 \\
46 \\
50 \\
59 \\
51 \\
55 \\
44 \\
37 \\
41 \\
38 \\
21 \\
52 \\
48 \\
38 \\
43 \\
42 \\
34 \\
41 \\
39\end{array}$ \\
\hline
\end{tabular}

* Dreyer's tables were used to give this figure. 
case (22) had a long and typical history ; radiologically the diaphragm was moderately low, nevertheless the reserve air was normal. I cannot explain this exception from the rule.

Table III shows the results in the patients with reduced vital capacity. It includes 35 cases with a reserve air of over $41 \%$, the upper limit of the normal, and 42 out of the 77 cases lie at or below $41 \%$. The mean of the total is $41 \%$ against $33 \%$

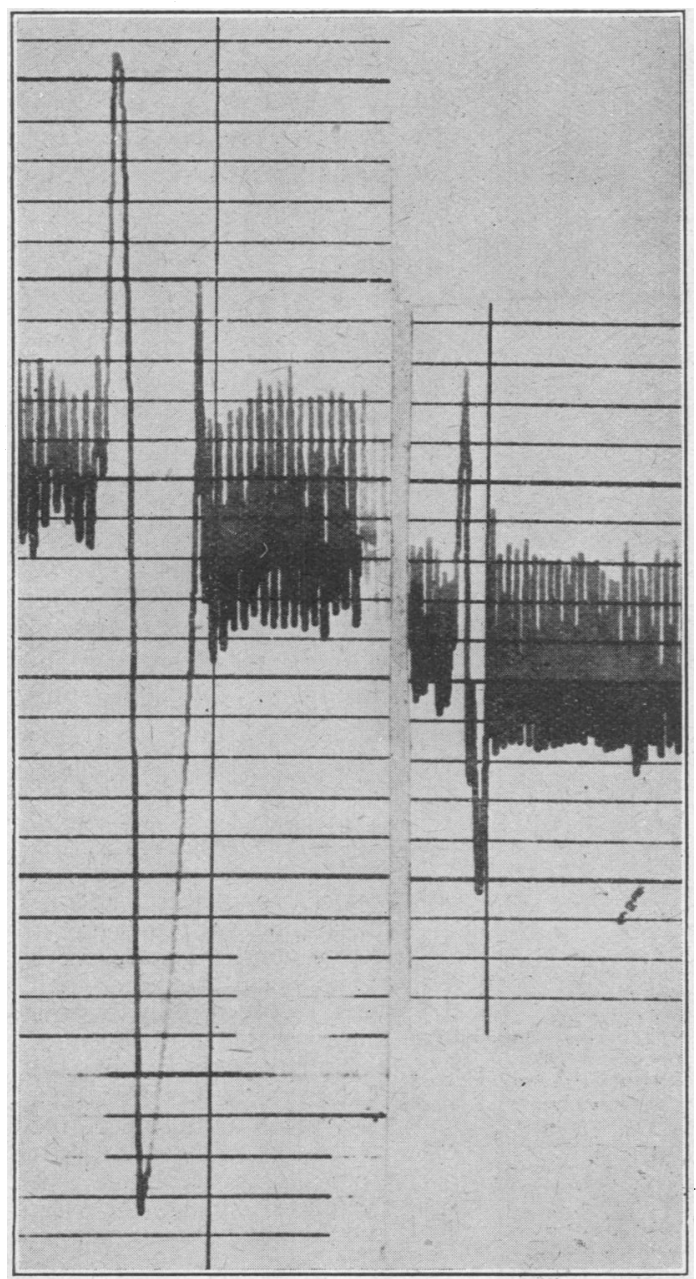

Fig. 5.-EFFect of Bronchial SPASM IN “ MASKING" A High RESERVE AIR.-The subject, M., showed an asthmatic state and emphysema. The tracing on the right was taken during an acute increase of the bronchospasm: vital capacity $1,340 \mathrm{ml}$., reserve air $27 \%$. Immediately afterwards $3 \%$ isopropyladrenaline was inhaled for two minutes and one minute later the tracing on the left was taken. The vital capacity is now $2,920 \mathrm{ml}$, the reserve air $50 \%$. in the normal subjects. The patients with a normal reserve air in this table probably have an abnormally large residual air. If they are given an antispasmodic drug and the bronchial spasm nearly always present in emphysema is relieved, vital capacity is found to increase. At the same time there is far more than a mere proportional increase in the reserve air which, in many cases, becomes abnormally large. An example of this is given in Fig. 5.

\section{Discussion}

It appears from this material that the reserve air has diagnostic importance. If the emphysematous condition (an enlarged mid-capacity) is created artificially, the reserve air increases. It must also be expected to increase as soon as the diaphragm is permanently kept at an abnormally low level. Finally, the expected increase is actually present in all "emphysematous" cases with a normal or high vital capacity. It may seem to be absent in those who have a reduced vital capacity, but in these it is often possible to show that an increased reserve air had been hidden or "masked" by the reduction in vital capacity. If the latter is brought back to normal, the reserve air becomes abnormally large.

This high percentage of reserve air in emphysema is no new discovery. The figures of Hurtado and others (1934) show, in the supine position, an average reserve air of $29.2 \%$ of the vital capacity in 26 cases of emphysema against a normal average of $17 \%-23 \%$ in different groups of subjects. Jimenez Diaz and others (1942) also found the reserve air increased. These authors drew no conclusions from this part of their findings. This may be because they did not disçriminate between severe and moderate cases, and therefore found many with apparently normal, but in fact " masked" high reserve air.

Our findings have been so regular that they may well improve our chances of recognizing moderate emphysema. We have found it most useful in practice, especially if used in conjunction with the radiological determination of the diaphragmatic level. If this is below normal and the reserve air increased, the diagnosis can be regarded as reasonably certain. It would be desirable to correlate these findings with the results of autopsy, but our material is not yet sufficient for this purpose.

Methodically, there are two difficulties. One is the "unmasking" of apparently normal reserve air. It may not be easy to find the optimum dose of a spasmolytic which increases the vital capacity. Apart from that, the bronchial obstruction 
may not be the only reason for the failure of the diaphragm to rise; the diaphragm itself may be atrophied and fibrosed (Fromme, 1916 ; Hitzenberger, 1927) and not capable of relaxing. But in these cases of severe emphysema the diagnostic difficulty is usually not great. If the reduced vital capacity is not caused by emphysema but by congestive failure, the spasmolytic drug used for "unmasking" is usually badly tolerated. In addition, the circulation time, which is prolonged in congestive failure but normal in emphysema, can be used for the differential diagnosis.

Another difficulty is that in a few sensitive patients an increased reserve air may be produced by the small resistance offered by the respiratory apparatus. Although the spirometer used in these investigations has never offered a higher resistance than $1.5 \mathrm{ml}$. of water, it could be observed by means of the thoracometer that some patients increased their chest circumference during the first minute of breathing and thus artificially produced a large reserve air. The slight resistance in the system acts in these subjects in the same way as a stenosis acts in normal persons (Fig. 1). In Fig. 6 a thoracometer tracing of such a subject sensitive to slight resistance is shown. At first, the patient breathed without the mouthpiece and without connexion with the spirometer. As soon as the mouthpiece was fitted and the connexion established, the chest circumference increased ; this indicated that some additional air had been retained in the chest. In the subsequent recording of the subdivisions of the vital capacity, this would

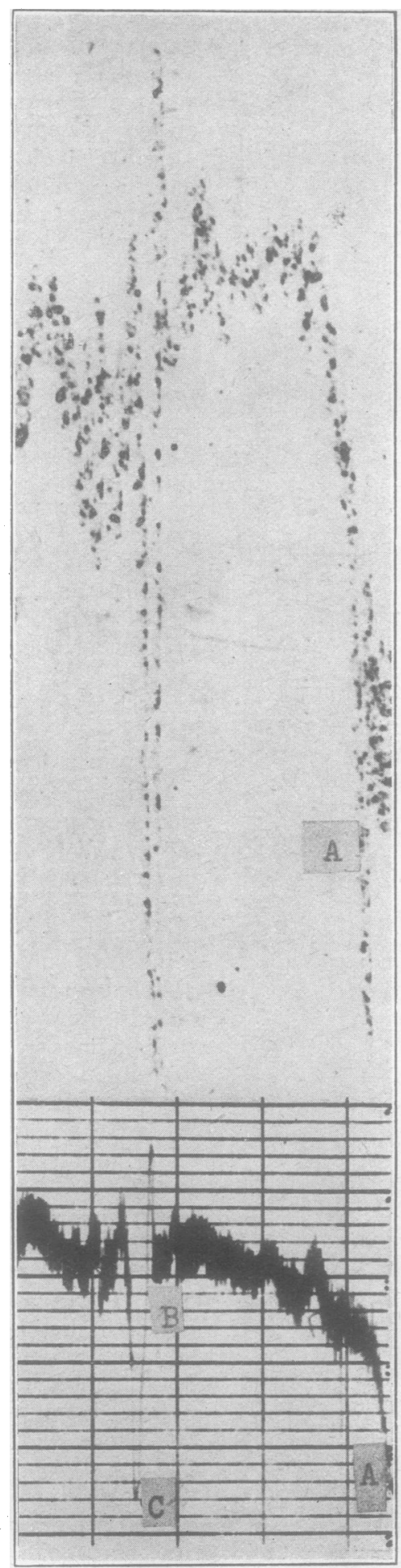

be expected to lead to an increase in the reserve air.

As a rule this phenomenon disappears at the second estimation of the vital capacity. For this reason one should not rely on one set of recordings if there is any suspicion that an increased reserve air might be caused by the resistance of the spirometer.

-If the reserve air is significantly increased in emphysema the complemental air would be expected to become correspondingly small. This is indeed the case, and the example in Fig. 3 shows the amount of its reduction, especially if the always variable tidal air be excluded. It might also be argued that the finding of an increased residual air is of a better diagnostic value than the reserve air. But the determination of the residual air in emphysema is more difficult than that of the reserve air ; and its results must become more doubtful when bronchial spasm shuts off large lung areas.

Fig. 6.-EFFeCt OF RESISTANCE OF SPIROMETER ON RESERVE AIR (upper tracing, thoracogram; lower tracing, spirogram). Before point A was reached, the subject's breathing had been recorded only by the thoracograph, which does not influence respiration. At A the subject was connected with the mouthpiece of the spirometer. It can be seen from the thoracogram that the chest expands at once, and that the spirogram shows after two minutes the enlarged reserve air typical for emphysema (BC). In this case the transient emphysema has been caused artificially by the resistance of the spirometer. (The line below $\mathbf{A}$ in the thoracogram was caused by a movement of the arm during the fitting of the mouthpiece.) 


\section{SUMmaRY}

The presence of a low level diaphragm in emphysema and the fact, shown in previous investigations, that the reserve air is mainly moved by the diaphragm, suggests that patients with emphysema in whom the respiratory muscles are unimpaired and able to overcome expiratory obstacles such as bronchial spasm must be expected to have an increased reserve air.

In artificial emphysema in normal subjects produced by means of an expiratory stenosis, the spirogram shows an increased reserve air and is in every respect similar to that of genuine emphysema.

A total of 123 emphysematous patients were examined. Of one group of 46 patients with a normal or high vital capacity all but three had an increased reserve air $(49 \%$ of the vital capacity against $33 \%$ in 48 normal subjects). In a second group of 77 patients with reduced vital capacity the reserve air was often found normal.

It was thought that a potentially large reserve air was being masked by inability to overcome bronchial spasm in these cases; the administration of spasmolytics "unmasked" a large reserve air.

An increased reserve air may be a useful diagnostic sign in emphysema, especially in conjunction with a radiologically determined low level diaphragm.

\section{REFERENCES}

Bass, E. (1924). Z. ges. exp. Med., 43, 223.

Christie, R. V. (1933). J. clin. Invest.. 12, 974.

Christie, R. V. (1944). Brit. med. J., 1, 105; 143.

Diaz, C. J., Agesa, A., and Alemany, M. (1942). Rev. clin. esp., 5, 24; 413.

Dreyer, G., and Hanson, G.F. (1920). Assessment of Physical Fitness. London.

Fromme, H. (1916). Virchows Arch., 221, 117.

Grossmann, M., and Herxheimer, H. (1948). . Brit. J. Radiol., 21, 446.

Herxheimer, H. (1948). Thorax, 3, 122.

Herxheimer, H. (1949). Thorax, 4, 65.

Hitzenberger, K. (1927). Das Zwerchfell im gesunden und kranken Zustand. Vienna.

Hurtado, A., Fray, W. W., Kaltreider, N. L., and Brooks, W. D. W. (1934). J. clin. Invest., 13, 169.

Hurtado, A., Kaltreider, N. L., Fray, W. W., Brooks, W. D. W., and McCann, W. S. (1935). J. clin. Invest., 14, 81.

Kaltreider, N. L., Fray, W. W., and Hyde, H. V. Z. (1938). Amer. Rev. Tuberc., 37, 662.

Siebeck, R. (1909). D. Arch. klin. Med., 97, 219.

Verzár, F. (1933). Pflüg. Arch. ges. Physiol., 232, 322. 